\title{
An evaluation of accessibility and content of microsurgery fellowship websites
}

\author{
Jiayi Hu MD ${ }^{1}$, Meng Zhen HBSc${ }^{2}$, Cristina Olteanu HBSc${ }^{3}$, Ronen Avram MD
}

\begin{abstract}
J Hu, M Zhen, C Olteanu, R Avram. An evaluation of accessibility and content of microsurgery fellowship websites. Plast Surg 2016;24(3):187-190.

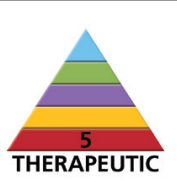

BACKGROUND: Websites for residency and fellowship programs serve as effective educational and recruitment tools.

OBJECTIVE: To evaluate the accessibility and content of fellowship websites that are commonly used by microsurgery applicants for career development.

METHODS: A list of one-year microsurgery fellowship websites (MFWs) was compiled by visiting the centralized American Society for Reconstructive Microsurgery (ASRM) website, followed by performing an extensive 'Google' search in October 2015. Accessibility of MFWs was assessed. Website content regarding key recruitment and education variables was also comprehensively reviewed. Website content was correlated with program characteristics using $t$ tests and ANOVA (two-tailed; $\mathrm{P}<0.05$ was considered to be statistically significant).

RESULTS: A list of 53 eligible programs was compiled. Only 15 of 51 (29\%) ASRM program links were functional. On average, the combined content from ASRM website and individual MFWs had 2.91 of 6 recruitment variables and 1.32 of 6 education variables, respectively. The majority of programs listed 'eligibility criteria' (87\%) and 'general information' (87\%). 'Evaluation criteria' were most poorly reported (4\%). Recruitment score was higher for United States programs compared with international counterparts ( $51 \%$ versus $33 \%$, respectively; $\mathrm{P}=0.02$ ). It was also higher in programs that focus on 'extremity' versus 'breast' ( $58 \%$ versus $37 \%$; $P=0.0028$ ). Education scores did not differ according to location, program size, subspecialty of focus or participation in the Microsurgery Match process.

CONCLUSION: Information regarding recruitment and education on most MFWs is scarce. Academic institutions should keep website content up to date and comprehensive to better assist candidates in the application process.

Key Words: Career development; Education; Fellowship; Microsurgery

\section{Une évaluation de l'accessibilité et du contenu de sites Web de surspécialisation en microchirurgie}

HISTORIQUE : Les sites Web pour les programmes de résidence et de surspécialisation sont des outils de formation et de recrutement efficaces. OBJECTIF : Évaluer l'accessibilité et le contenu des sites Web de surspécialisation souvent utilisés par les candidats en microchirurgie en vue de leur perfectionnement de carrière.

MÉTHODOLOGIE : Les chercheurs ont compilé la liste des sites Web de surspécialisation en microchirurgie (SSW) d'un an à partir du site Web centralisé de l'American Society for Reconstructive Microsurgery (ASRM), puis ont effectué une recherche complète dans Google en octobre 2015. Ils ont évalué l'accès au SSW et procédé à une analyse détaillée des variables liées au recrutement clé et à la formation. Ils ont corrélé le contenu des sites Web avec les caractéristiques des programmes au moyen du test de Student et de l'analyse de variance (bilatéraux; $\mathrm{P}<0,05$ était considéré comme statistiquement significatif).

RÉSULTATS : Les chercheurs ont compilé une liste de 53 programmes admissibles. Seulement 15 liens sur les 51 programmes de l'ASRM (29\%) étaient fonctionnels. En moyenne, le contenu combiné du site Web de l'ASRM et des SSW individuels disposait de 2,91 des six variables de recrutement et de 1,32 des six variables de formation, respectivement. La majorité des programmes comportaient un volet "Critères d'admissibilité " $(87 \%)$ et un volet « Renseignements généraux » $(87 \%)$. Les « critères d'évaluation » étaient moins bien définis (4\%). Le score de recrutement était plus élevé aux États-Unis que dans les programmes internationaux (51\% par rapport à $33 \%$, respectivement; $\mathrm{P}=0.02$ ). Il était également plus élevé dans les programmes axés sur les membres que sur les seins (58\% par rapport à $37 \% ; \mathrm{P}=0,0028)$. Les scores de formation étaient similaires à l'égard du lieu, de la dimension du programme, de la surspécialisation d'intérêt ou de la participation au processus de jumelage en microchirurgie. CONCLUSION : Il y a peu d'information relative au recrutement et à la formation dans la plupart des SSM. Les établissements universitaires devraient maintenir le contenu de leur site à jour et complet afin de mieux aider les candidats dans le cadre de leur processus de candidature.

websites have been studied in a variety of medical specialties, similar studies have not examined MFWs (7-9). Given that most program websites are inaccessible with low-quality content as reported by previous studies, we hypothesized that MFWs are in a similar situation.

Program list compilation

\section{METHODS}

While microsurgery fellowships are offered worldwide, those recognized by the ASRM are considered to be well established. Maldonado and Song (2) made important distinctions between United States (US)-based programs, which are more "hands-on", and their European counterparts, which are "observational". Therefore, the programs included in the present study were compiled from the ASRM website (accessed October, 2015), which were all one year in duration. A 'Google' (Google, USA) search was also performed by using the keywords "microsurgery fellowship" and reviewing results of the first 30 pages. This was to identify any other programs that were also one-year long and provided hands-on surgical exposure. adopted by the European programs to facilitate microsurgery training.

While program websites are routinely considered to be crucial resources for applicants, and the accessibility and content of such

${ }^{1}$ Division of Plastic Surgery, Department of Surgery; ${ }^{2}$ Faculty of Medicine, McMaster University, Hamilton; ${ }^{3}$ Faculty of Medicine, University of

Toronto, Toronto, Ontario

Correspondence: Dr Jiayi Hu, Division of Plastic Surgery, Department of Surgery, McMaster University, B3-149, Juravinski Hospital,

711 Concession Street, Hamilton, Ontario L8V 1C3. Telephone 905-521-2100 ext 73962, fax 905 521-9992,

e-mail jiayi.hu@medportal.ca 


\section{Accessibility}

The program links on the ASRM website were checked for accessibility. Website links were assessed to be functional, nonfunctional or incorrect (linked to other sites). In addition, each program was searched in Google using the keywords "program name" and "microsurgery fellowship". A website was considered to be accessible if a functional link could be found within the first five pages of the search results.

\section{Website evaluation: recruitment and education}

Information for each program was collected by accessing the ASRM website as well as individual MFWs. This process was performed by two independent reviewers ( $\mathrm{MJ}$ and $\mathrm{CO}$ ), and the results were reviewed by a resident and staff surgeon to resolve any discrepancies. Recruitment and education variables that were deemed important program components by the Accreditation Council of Graduate Medical Education were assessed for each program. They were recorded as 'present' or 'absent', without evaluating the quality of the information.

The following recruitment variables were evaluated: general program description, salary amount, selection criteria, eligibility criteria, requirement for USMLE/ECFMG (United States Medical Licensing Exam/Education Commission for Foreign Medical Graduates), and listing of current or past fellows. The salary may be mentioned either in specific amount, or to be commensurate with a specific level of residency training. Selection criteria refer to how one's application is evaluated. Eligibility criteria state the training qualification required before fellowship application. USMLE/ECFMG requirements are only applicable for US-based programs.

In addition, the following education variables were evaluated: evaluation criteria, research description, journal club, specific rotations, didactic teaching and grants for conferences. Evaluation criteria state how the fellow's progress would be evaluated throughout the fellowship program. Research description mentions specific research interest, requirement, and/or any facilities or resources available, such as animal laboratories and biostatisticians. Simply stating that "research is available" was not sufficient. Specific rotations would be shown in a schedule that lists various clinical placements. Grants for conferences should include whether the fellow receives support to attend conferences.

\section{Program comparison}

Based on the above-mentioned criteria, each program would receive a score in both the recruitment and education domains (calculated as a percentage score based on the six variables). Fellowship programs were then compared according to location ('US' versus 'international'), program size (' 1 fellow' versus ' $>1$ fellow'), and whether they participate in the San Francisco Match for Microsurgery (10). In addition, recruitment and education scores were compared between programs with different subspecialty focus ('Breast', 'Extremity' or 'General'). The program focus was determined by analyzing the program description.

\section{Statistical analysis}

Website accessibility was compared between accessing program links on the ASRM website and retrieving program websites via Google searches. This was accomplished using Fisher's test $(\mathrm{P}<0.05$ was considered to be statistically significant). Other comparisons were performed using $t$ test (two-tailed; $\mathrm{P}<0.05$ was considered to be statistically significant). ANOVA was used to compare between different subspecialties (two-tailed; $\mathrm{P}<0.05$ was considered to be statistically significant). All statistical analyses were performed using Excel 2013 (Microsoft Corporation, USA).

\section{RESULTS}

\section{Accessibility}

Both the ASRM website and Google search were evaluated for program accessibility. As of October 2015, the ASRM website had a list of 51 programs. The Google search found an additional two programs
(53 programs in total). The accessibilities of program websites are shown in Table 1, demonstrating that the Google search was more effective in retrieving functional program links. Only 29\% of the programs listed on the ASRM had functional links (15 of 51), compared with $77 \%$ by Google search.

\section{Fellow recruitment}

The microsurgery programs had an average of 2.91 of $6(49 \%)$ recruitment variables (Figure 1). Most programs reported general program description (87\%), salary amount (62\%) and eligibility criteria (87\%). Fewer programs reported USMLE/ECFMG (30\%), fellow listing $(25 \%)$ and selection criteria (6\%).

\section{Fellow education}

The programs had an average of 1.32 educational variables of $6(22 \%)$ (Figure 2). Most programs provided a specific description for research activities (58\%). However, the other variables were poorly reported: evaluation criteria (4\%); specific rotations (6\%); journal club (15\%); grants for conferences (22\%); and didactic teaching (26\%).

\section{Program comparison}

The recruitment and education scores were expressed as a percentage and compared between the following variables: location, program size, participation in the match and subspecialty (Tables 2 to 4). Most of the programs were located in the US (45 programs) and had one fellow only (34 programs). There was an even divide of programs regarding match participation and subspecialties.

Recruitment score was significantly higher in US programs compared with their international counterparts ( $51 \%$ versus $33 \%$, respectively; $\mathrm{P}=0.02$ ). In addition, website content on recruitment was more effectively shown in programs that focused on 'extremity' versus 'breast' ( $58 \%$ versus $37 \%$; $\mathrm{P}=0.0028$ ). On the other hand, education scores did not differ by any of the previously mentioned variables.

\section{DISCUSSION}

Fellowship training is an invaluable opportunity that enables medical graduates to be intellectually stimulated while improving their clinical skills and competitiveness for the job market (11). While online education resources have been increasingly implemented in the niche field of microsurgery, the centralized ASRM website has rather poor accessibility to individual program websites (29\% of the links were functional), despite it being an important resource for prospective microsurgical trainees $(2,12,13)$. This result was not surprising, but rather, consistent with findings in similar studies. Mulcahey et al (14) reviewed accredited sports medicine fellowship websites and concluded that only $54 \%$ of the links were accessible from the American Orthopedic Society of Sports Medicine database, and that only 5\% of the links were functional from the San Francisco Match database.

On the other hand, Google searches yielded more functional MWFs than the ASRM website. Similar findings were confirmatory in other studies, which meant that centralized organizational websites were not updated on a regular basis $(14,15)$. In addition, despite conducting extensive Google searches, not all programs had a functional website. Collectively, these results suggest that the ASRM, similar to many other medical organizations, as well as individual surgical training institutions, did not optimize their website accessibility to facilitate fellowship application for prospective candidates.

In addition, the website content (combined from the ASRM website and individual MWFs) for programs were of very poor quality. On average, only $49 \%$ and $22 \%$ of recruitment and educational programs were reported, respectively. Combined with low accessibility, these findings suggest that the current state of MWFs may negatively affect an applicant's interest in applying to certain programs or subspecialties, as the literature has shown $(3,4)$.

In a recent study of hand surgery fellowship websites (HFWs), Silvestre et al (15) showed that the orthopedics-operated HFWs had higher education scores and a trend toward better accessibility than the plastics-operated HFWs. We observed a similar finding in the 


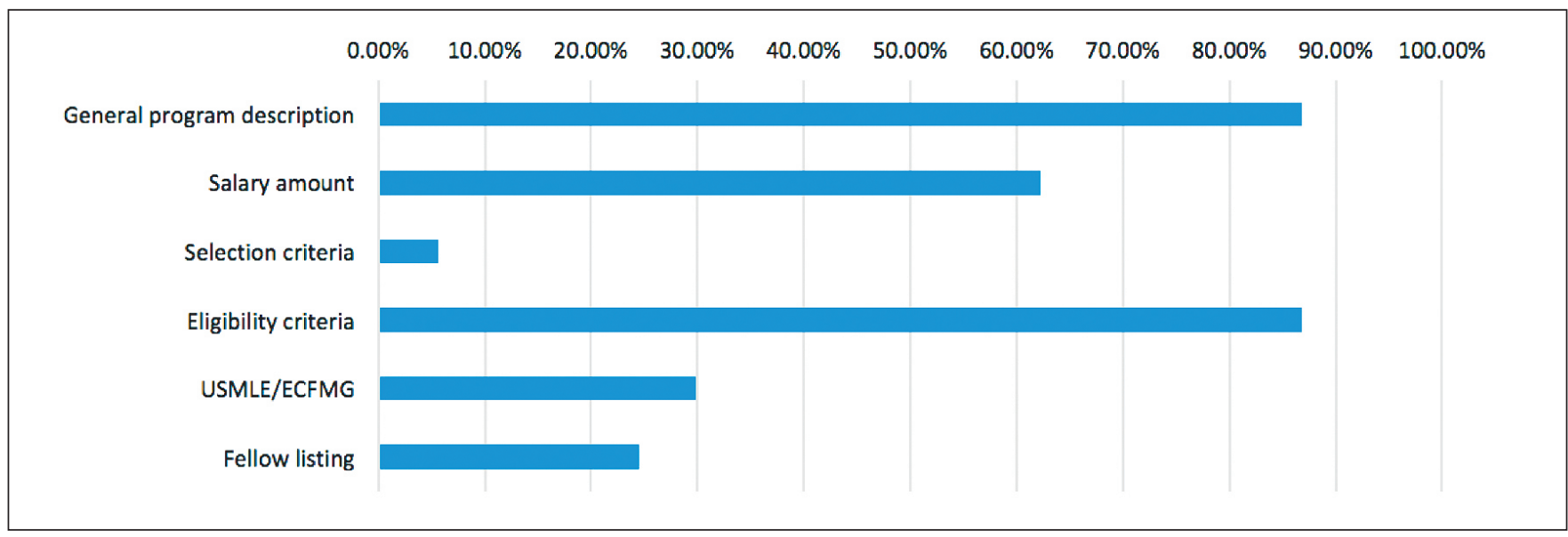

Figure 1) Quality of recruitment content on microsurgery fellowship websites. USMLE/ECFMG United States Medical Licensing Exam/Education Commission for Foreign Medical Graduates

\begin{tabular}{|c|c|c|c|c|c|c|c|}
\hline $0.00 \%$ & $10.00 \%$ & $20.00 \%$ & $30.00 \%$ & $40.00 \%$ & $50.00 \%$ & $60.00 \%$ & $70.00 \%$ \\
\hline \multicolumn{8}{|l|}{ Specific research description } \\
\hline \multicolumn{8}{|l|}{ Fellow evaluation criteria } \\
\hline \multicolumn{8}{|l|}{ Specific rotations } \\
\hline \multicolumn{8}{|l|}{ Journal club } \\
\hline \multicolumn{8}{|l|}{ Didactic teaching } \\
\hline Grants for conferences & & & & & & & \\
\hline
\end{tabular}

Figure 2) Quality of education content on microsurgery fellowship websites

TABLE 1

Accessibility of microsurgery websites comparing the American Society for Reconstructive Microsurgery (ASRM) website and Google (Google, USA) search

\begin{tabular}{lccc}
\hline Source & $\begin{array}{c}\text { Functional links of } \\
\text { total programs, } \mathbf{n}(\%)\end{array}$ & $\begin{array}{c}\text { Total } \\
\text { programs, } \mathbf{n}\end{array}$ & $\mathbf{P}$ \\
\hline ASRM website & $15(29)$ & 51 & 0.001 \\
Google search & $41(77)$ & 53 & \\
\hline
\end{tabular}

present study in that 'extremity' programs (partially orthopedics operated) had higher recruitment scores than 'breast' programs (entirely plastics operated), while the education scores were not different. This is perhaps because plastic surgery programs are smaller in size than orthopedics, and that fellowship programs are less incentivized to develop high-quality websites for a significantly smaller community. However, despite the fact that microsurgery is a competitive fellowship program with limited positions, unfilled positions are still in significant proportions after the match (seven of 35 positions in 2014, and four of 37 positions in 2015). Therefore, one may hypothesize that, by improving the accessibility and content quality of MFWs, it may improve the candidate recruitment process. Despite the fact that the Microsurgery Match has existed since 2010, only in the last year did the match provide a centralized application process for the first time. We hope that this centralized administrative process would encourage participating MFWs to keep their online content comprehensive and up to date.
TABLE 2

Recruitment score comparison between program variables

\begin{tabular}{lccc}
\hline Variable & Programs, $\mathbf{n}$ & $\begin{array}{c}\text { Recruitment } \\
\text { score, } \%\end{array}$ & $\mathbf{P}$ \\
\hline Location & & & \\
$\quad$ United States & 45 & 51 & 0.02 \\
$\quad$ International & 8 & 44 & \\
Program size & & & \\
$\quad 1$ fellow & 34 & 47 & 0.51 \\
$>1$ fellow & 19 & 50 & \\
Match participation & & & \\
Yes & 25 & 38 & 0.87 \\
$\quad$ No & 28 & 39 & \\
Subspecialty & & & \\
Breast & 15 & 37 & 0.009 (ANOVA) \\
Extremity & 18 & 58 & \\
$\quad$ General & 20 & 46 & \\
\hline
\end{tabular}

It was not surprising to witness the recruitment score being higher in the US-based programs than international programs. This is likely because most US-based programs have a long-established history and that the ASRM website is also US founded.

There were several limitations to our study. First, it was a crosssectional analysis conducted during a specific time period. Online content may be evolving as application deadlines for upcoming cycles approach. Second, for programs without an accessible website, we did 
TABLE 3

\begin{tabular}{ll} 
Website content recruitment score comparison between \\
subspecialties \\
\hline Comparison & $\mathbf{P}$ \\
\hline Breast versus extremity & 0.0028 \\
Extremity versus general & 0.19 \\
Breast versus general & 0.053 \\
\hline
\end{tabular}

not contact the programs to investigate whether the website was truly inaccessible, or that the website was functional but not retrievable based on our search methodology. In addition, we did not survey informational needs from microsurgery applicants. However, based on the Accreditation Council of Graduate Medical Education guideline and various similar studies, we believe the recruitment and education variables investigated in the present study are highly important to microsurgery fellowship candidates.

\section{CONCLUSION}

There is a paucity of quality program information regarding the official ASRM website and individual MFWs for microsurgery applicants. The current state of MFWs certainly does not reflect the "high level of accuracy" and "precise skills" required by microsurgery (2). Academic associations and institutions should seek opportunities to keep the online content of MFWs up to date and comprehensive to utilize them as effective recruitment and educational resources.

\section{REFERENCES}

1. Herrera FA, Chang EI, Suliman A, Tseng CY, Bradley JP. Recent trends in resident career choices after plastic surgery training. Ann Plast Surg 2013;70:694-7.

2. Maldonado AA, Song DH. European and American microsurgery training programs: The fellowship concept difference. Plast Reconstr Surg 2015:136:292e-293e.

3. Graeta TJ, Birkhahn RH, Lamont D, Banga N, Bove JJ. Aspects of residency program's web sites important to student applicants. Acad Ererg Med 2005;12:89-92.

4. Chu LF, Young CA, Zamora AK, et al. Self-reported information needs of anesthesia residency applicants and analysis of applicantrelated web sites resources at 131 United States training programs. Anesth Analg 2011;112:430-9.

5. Rozenthal TD, Lonner JH, Parekh SG. The Internet as a communication tool for academic orthopaedic surgery departments in the United States. J Bone Joint Surg Am 2013;95:e85.

6. Microsurgery Program List on ASRM website. <www.microsurg.org/ fellowships/list/> (Accessed October 2015).

7. Silvestre K, Tomlinson-Hansen S, Fosnot J, Taylor JA. Plastic surgery residency websites: A critical analysis of accessibility and content. Ann Plast Surg 2014;72:265-9.

8. Trehan SK, Morrell NT, Akelman E. Accredited hand surgery fellowship web sites: Analysis of content and accessibility. 2015;40:778-82.
TABLE 4

Website content education score comparison between program variables

\begin{tabular}{lccc}
\hline Variable & Programs, $\mathbf{n}$ & Education score, \% & $\mathbf{P}$ \\
\hline Location & & & \\
United States & 45 & 23 & 0.61 \\
International & 8 & 19 & \\
Program size & & & \\
$\quad 1$ fellow & 34 & 20 & 0.23 \\
$>1$ fellow & 19 & 26 & \\
Match participation & & & 0.65 \\
Yes & 25 & 12 & \\
No & 28 & 14 & \\
Subspecialty & & & 0.12 \\
Breast & 15 & 12 & (ANOVA) \\
Extremity & 18 & 27 & \\
General & 20 & 21 & \\
\hline
\end{tabular}

DISCLOSURES: The authors have no financial disclosures or conflicts of interest to declare.

9. Embi PJ, Desai S, Cooney TG. Use and utility of Web-based residency program information: A survey of residency applicants. J Med Interes Res 2003;5:e22.

10. San Francisco Match, Microsurgery. <www.sfmatch.org/ SpecialtyInsideAll.aspx?id=26\& typ $=1 \&$ name $=$ Microsurgery $>$ (Accessed October 2015).

11. Morrell NT, Mercer DM, Moneim MS. Trends in the orthopedic job market and the importance of fellowship subspecialty training. Orthopedics 2012;35:e555-e560.

12. Satterwhite T, Son J, Carey J, et al. Microsurgery education in residency training: Validating an online curriculum. Ann Plast Surg 2012;68:410-4

13. Taylor NW, Webb K, Neumeister MW, Bueno RA Jr. Assessment of resident microsurgical skill using an online video system. Plast Reconstr Surg 2014;133:78e-79e.

14. Mulcahey MK, Gosselin MM, Fadale PD. Evauation of the content and accessibility of web sites for accredited orthopedic sports medicine fellowships. J Bone Joint Surg Am 2013;95:e85.

15. Silvestre J, Guzman JZ, Abbatematteo JM, Chang B, Levin LS. Evaluation of content and accessibility of hand fellowship websites. Hand 2015;10:516-21. 